\title{
Experimental Evaluation of Consolidation Techniques of Fossiliferous Limestone in Masonry Walls of Heritage Buildings at Historic Jeddah, Kingdom of Saudi Arabia
}

\author{
Yaser Y. Abdel-Aty ${ }^{\text {a }}$, Hassan S. Mahmoud ${ }^{\text {b }}$, Abdulnaser A. Al-Zahranic \\ a. Conservation Department, Faculty of Archaeology, Cairo University, 12613 Giza, Egypt. \\ b. Conservation Specialist, Ministry of Tourism and Antiquities, Egypt. \\ c. Department of Heritage Management, Faculty of Tourism and Archaeology, King Saud University, \\ Riyadh, Kingdom of Saudi Arabia.
}

\section{HIGHLIGHTS}

- The heritage masonry buildings in Historic Jeddah are commonly constructed of fossiliferous limestone blocks (called "Mangabi").

- The "Mangabi" limestone usually suffers from high porosity, low density and weak mechanical strength.

- This research experimentally demonstrated the preeminence of nano-lime in consolidating "Mangabi" limestones over Wacker OH100.

\section{ARTICLE INFO}

\section{Article History:}

Received: 1 May 2020

Revised: 6 June 2020

Accepted: 6 September 2020

Available online: 7 September 2020

Keywords:

Historic Jeddah, Fossiliferouslimestone; Nano-lime; Wacker $\mathrm{OH}$ 100; Consolidation.

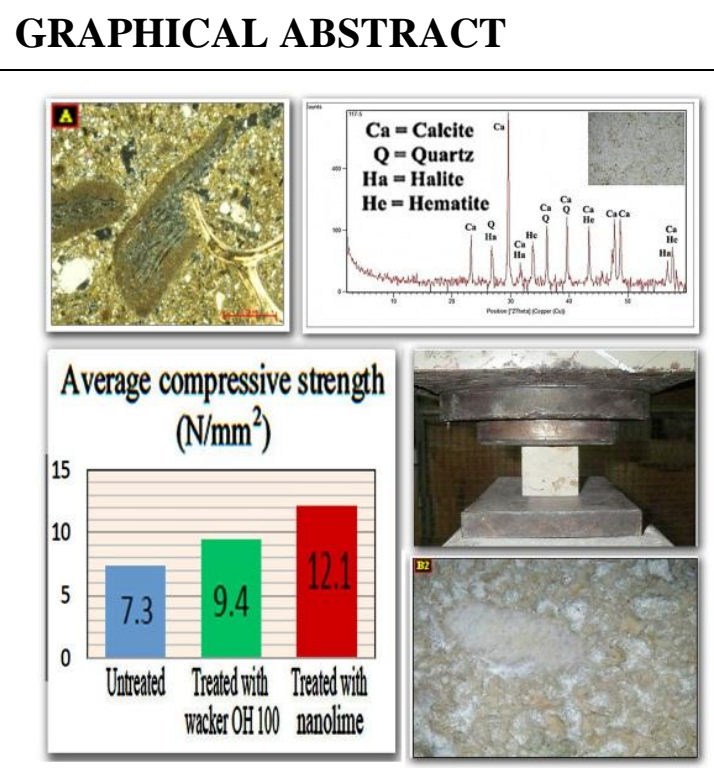

\begin{abstract}
The Historic Jeddah city is the forefront of the Saudi Arabia heritage sites that UNESCO recently registered in the World Heritage List. Most of its buildings were constructed with multiple-leaf masonry walls using marine-origin of fossiliferous limestone that vernacular name is "Mangabi". These stones are characterized by high porosity, low density and weak mechanical strength. Unfortunately, most of previous studies merely concerned architectural aspects of these buildings and their urban.
\end{abstract}

\footnotetext{
*Corresponding author: yaser_yehya @cu.edu.eg
} 
This paper presented some parts of the intensive experimental campaign by the authors that focused on various structural aspects and strengthening techniques of these buildings. It aimed to evaluate the enhancement of physical and mechanical properties of their stones by injection with either nano-lime or Wacker OH-100. Different parameters were taken into consideration to evaluate the short-term efficacy of the consolidating materials after both treatments. Thirty-six cubic stone specimens of $50 \mathrm{~mm}$ side-length were prepared from ruins of unregistered heritage buildings. Twelve specimens were treated with the nano-lime 'CaLoSiL ${ }^{{ }_{1} 1}$ of IP5, E25 and E50 ready concentrations, using brushing and injection, while another twelve were treated with Wacker $\mathrm{OH}-100$. Both types were left thirty days for polymerization and carbonation processes of the consolidants to complete in standard conditions. Then, standard physical (i.e. bulk density, apparent porosity and water absorption) and uniaxial compression tests were conducted for both untreated and treated specimens (three specimens per each test). Besides, X-Ray diffraction and digital, polarizing and scanning electron microscopes were utilized for microstructure examinations of the specimens. Results and recommendations were derived.

\section{Introduction}

The Kingdom of Saudi Arabia (KSA) for decades through the Saudi Commission for Tourism and Antiquities (SCTA) has worked hard to preserve, register and enrich the national architectural culture resources all around the Kingdom. The SCTA has chosen the Historic Jeddah city (Fig. 1-a) to be the forefront of the national heritage sites together with "Madain Saleh" and "Historic Dir'iya". In 2014, the UNESCO has registered the three sites in the World Heritage List (WHL). Established in $646 \mathrm{AD}$, the old Jeddah sites have long history that extends from the pre-Islamic eras and through all the following centuries until the present. The main old district of Jeddah that named as "Al-Balad" (Fig. 1-b) possesses hundreds (over 500) of unreinforced stone-masonry (URM) buildings that are recognized as historic [1]. The authors achieved intensive survey over more than 50 of the heritage buildings of the Old Jeddah, whether slightly or severely damaged, besides the ruined ones (Fig. 2). The survey applied various micro-sampling and testing techniques over unregistered ruins that ranged from visual observations until standard physical, chemical, petrographic, microscopic and mechanical methods. This paper demonstrated part of these intensive experimental campaigns. The visual observations revealed that the walls of these buildings are generally built of multipleleaf (three layers) URM loadbearing system (Fig. 2). They are constructed from local stones that are vernacularly named as "Mangabi". These stones are fossiliferous-limestone that is characterized by shell-formation inside, low density, very high porosity and low mechanical strength. Nevertheless, these stones have high resistance to humidity, heat isolation and are abundantly available, thus it was found in all historic buildings. Figure 2 (a - d) showed various typologies of these URM walls of heritage buildings in Historic Jeddah, which have slender, moderate and wide thickness walls. The external layers are built of stone blocks while the inner core is built of rubble stones in abundance of lime mortar. Over most of the surveyed heritage buildings' walls, very few (i.e. the average is about one or two blocks for every $20 \mathrm{~m}^{2}$ area of the wall surface) of the outer-leaf stone blocks are of coral type, while most of the stone blocks are of the fossiliferous 

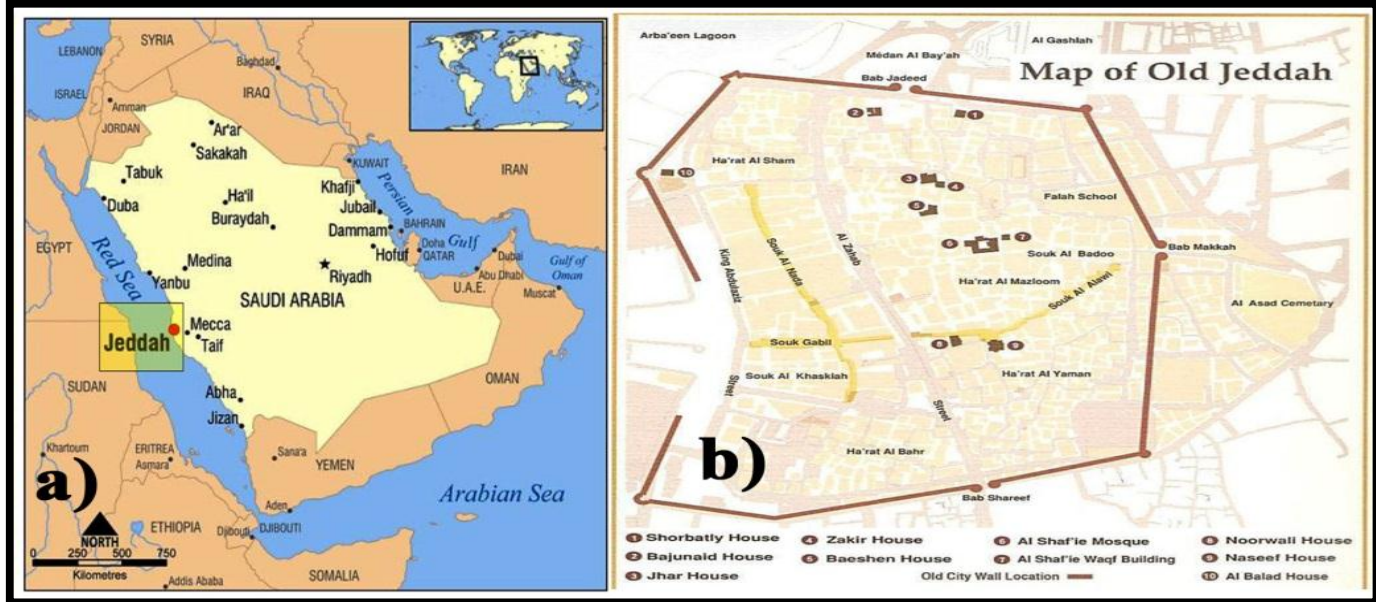

Fig.1: Maps of the Jeddah City: a) the location of Jeddah in the Kingdom of Saudi Arabia (After: www.mapsof.net/map/jeddahsaudi-arabia); b) the old district of Jeddah "Al-Balad" (After: M. Bagader [1]).

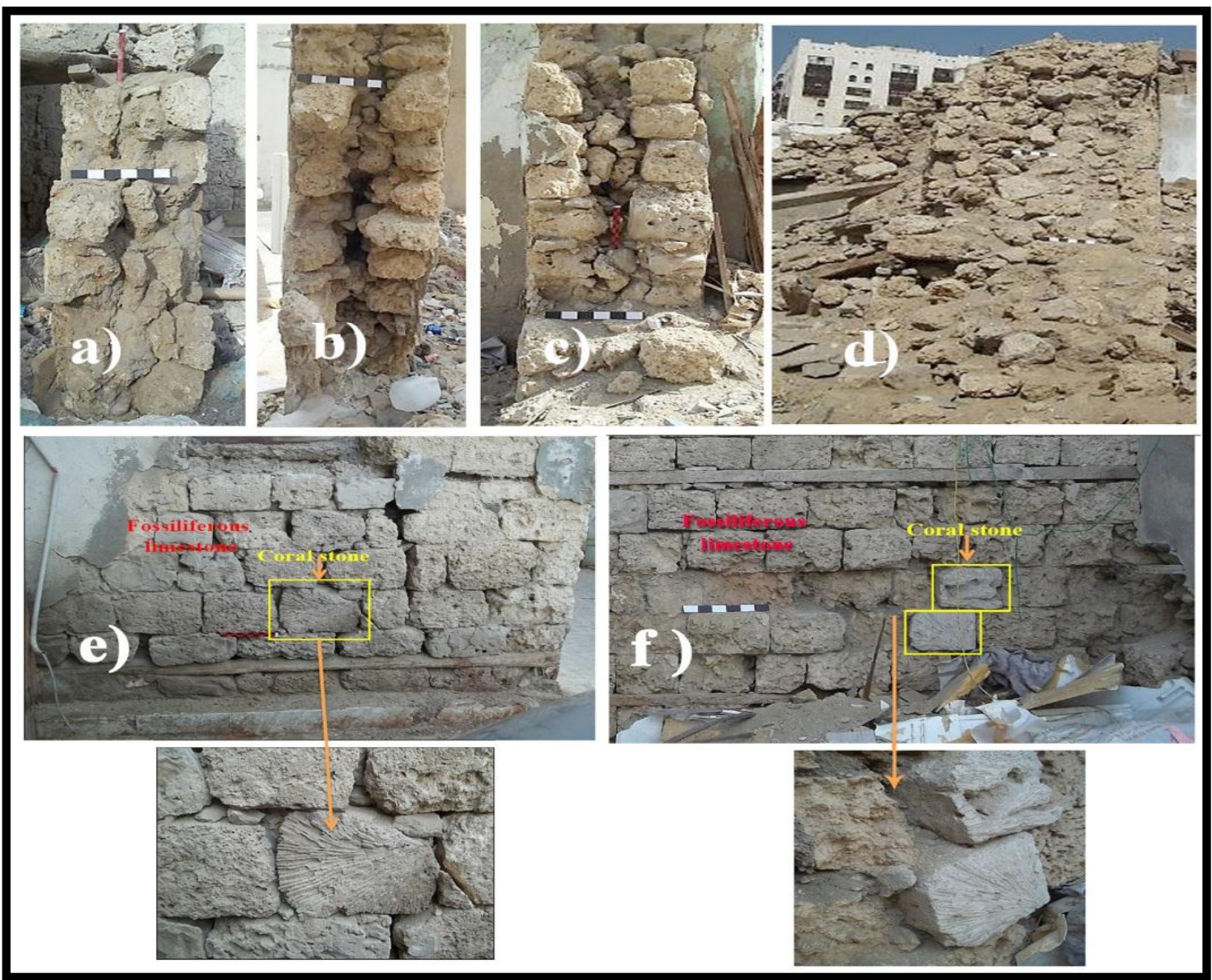

Fig. 2: Examples of the major types of the multiple-leaf stone masonry walls and their stone blocks of the heritage buildings at Historic Jeddah: a) ,b) small thickness (0.45-0.55 m); c) medium thickness (0.6-0.8 m); d) large thickness (> 1 $\mathrm{m})$; e) and f) show the majority (almost all) of the stone blocks are fossiliferous limestone, while very few (one or two) are coral stone units. 
limestone type (Fig. 2-e, 2-f), which were only considered in this research.

The fossiliferous limestone in the Jeddah heritage buildings is termed 'Biosparite' limestone under the 'Folk' classification of sedimentary rocks [2]. It is an organic limestone, made mostly of calcium carbonate $\left(\mathrm{CaCO}_{3}\right)$ in the form of calcite mineral (or Aragonite at early stages of formation), that contains an abundance of fossils or fossil traces. It was originally cut from a fine sandy to silty fossiliferous carbonate rock consisting of skeletal allochems and quartz grains embedded mainly in silty lime-mudstone (micrite). Petrographically, this rock type is highly fossiliferous that is composed of molluscan shells, echinoid spines, benthonic foraminiferal and algal skeletals fragments [3]. The shell fragments demonstrate the original internal microstructure with fine fibours wall, vesicular tissue and fine cellular structure. Some allochems (e.g. echinoid spines) are composed of fine elongated empty cavities surrounded by dark micritic envelope. The main cavities of the molluscan shells (e.g. gastropoda) are partially filled by silty micrite. Some bivalves chambers are filled with quartz silty grains that amalgamated by iron oxide stained micrite paste (Fig. 3). The fossils in these rocks may be of macroscopic or microscopic size. These carbonate rocks are usually found associated with coral reefs [2], and are effectively sediment made up primarily of calcium rich skeletons and shells of sea creatures. These sediments, through various geological processes, were laid down millennia ago in layers of what eventually became calcium rich stone. Limestone will often show some of the fossilised shells of these ancient sea creatures in its make up [3].

Unfortunately, very few previous studies and researches were conducted that concern these buildings, which mostly covers architectural and urban studies [4-6].
Consequently, the authors have conducted intensive survey and experimental campaign to study all structural aspects of the URM walls of these heritage buildings of Historic Jeddah. The present work presented part of these campaign and research study, which focuses on the experimental investigation of the building stones of the outer leaf of the URM walls at Heritage buildings of Historic Jeddah. The poor mentioned properties of the fossiliferous-limestone of "Mangabi" type caused most of structural deficiencies and damages generally found in these walls, such as fragmentation of stone blocks, vertical cracking in walls, etc. Consequently, it is essential to consolidate the stones of the surface layers with their internal structure and to isolate them from different sources of surrounding moisture. This would raise the overall mechanical strength of the URM loadbearing walls and enhance the structural safety levels of the heritage buildings against various affecting loads.

The experimental investigation was conducted over the "Mangabi" stone specimens, which were extracted from ruins of a number of unregistered heritage buildings. These stones were originally brought from quarries at North of Jeddah, along its seashore and from "AlManqabah" lagoon located its NorthWest [4]. They were cut into cubes of average side dimensions $50 \mathrm{~mm}$. Generally, the products used for consolidation and strengthening of traditional building stones in heritage buildings should be compatible, from the chemical, mechanical, physical and aesthetical point-ofview, with the substrate on which they are applied [8]. Organic consolidants such as acrylic and epoxy resins have generally low durability and compatibility when applied to calcareous substrates [9]. Tetraethyl orthosilicate, often referred to as ethyl silicate or silicic acid ester, is currently one of the most used 
consolidants for limestone, mainly because of the lack of more adequate alternatives. Although, these silicate-based products can deeply penetrate into porous materials, they have low chemical compatibility with calcareous substrates and in some cases low effectiveness and durability [10]. Contrarily, inorganic-based consolidants such as barium hydroxide and limewater have a high physicochemical compatibility with the substrate and good durability, although their use requires a large number of applications, while the consolidation achieved is not always respectably effective. Also, the limewater technique does not produce a noticeable consolidation, as most of the lime is deposited within the outer $2 \mathrm{~mm}$ and the low amount of particles does not produce consolidating effect. Hence, the use of nano-lime in alcohol allows incorporation of larger amounts of lime into the treated substrate with far less water, yielding improved penetration and faster carbonation [11].

The main aim of this study is to enhance the physical and mechanical properties of the porous and low strength "Mangabi" stone-blocks in Jeddah's heritage buildings. For this purpose, a short-term efficacy of nano-lime (i.e. $\mathrm{Ca}(\mathrm{OH})_{2}$ nanoparticles) and Wacker $\mathrm{OH}-100$ consolidations of the limestone is evaluated by testing bulk density, apparent porosity, water absorption and compressive strength for the studied specimens, before and after treatment. Density and porosity are the most important factors in assessing the mechanical properties of stone units. The density of specimens may inform about the tightness of the rock components which will affect the overall properties of the rock [12]. Density and porosity are often related to the strength of rock materials. A low-density and high-porosity rock usually has low strength. The porosity of rocks is one of the prime determining factors with re- spect to rock durability as construction materials [13-15]. Water absorption is an important rock index depending on mineralogy and porosity of rock. Porosity is one of the governing factors for the permeability and it provides the void for water to flow through a rock material. High porosity therefore naturally leads to high permeability [15].

The nano-lime of $\mathrm{CaLoSiL}^{\circledR}{ }^{\circledR}$, which is $\mathrm{Ca}(\mathrm{OH})_{2}$ particles with sub-micrometric dimensions, represents one of the modern consolidants that are applied in many $\mathrm{Eu}-$ ropean and Middle-East countries for the treatment of heritage calcareous substrates (i.e. stones and plasters). Its treatment derived from an older limewater technique, which was traditionally used for its high compatibility with the calcareous matrix, while it requires a large number of applications and it does not always yield in highly effective consolidation results. Since 2001, alcoholbased dispersions of nano-particles of calcium hydroxide $\mathrm{Ca}(\mathrm{OH})_{2}$ have been synthesised to overcome the limitations of the limewater treatment. Nano-limes present the same high compatibility and durability of the traditional technique but better properties achieved in terms of higher consolidation, penetration, reactivity and fewer side effects [16-17]. As nano-lime particle size ranges between 1 to $100 \mathrm{~nm}$ [18], it is smaller than the pore size range of porous and carbonated stones. This research showed that nanolime can be an effective, deep penetrating consolidant for various types of limestone. There are two commercially available brands of nano-lime, the CaLoSiL ${ }^{\circledR}$ that was introduced to the market in 2006 and the Nano-restore that appeared in 2008. The treatment product $\mathrm{CaLoSiL}^{\circledR}$ is available in various concentration of $\mathrm{Ca}(\mathrm{OH})_{2}$ from 5 to $50 \mathrm{gm} /$ litre in different alcohols [18]. The alcohol can be ethanol, isopropanol or n-propanol [19]. 
It is worth mentioning that the selection of the two consolidants refers to results of previous researches and studies of the authors and others [12-21] that recommended application of these types with sedimentary building stones and mortars of similar conditions of the Historic Jeddah masonry buildings.

\section{Materials and methods}

\subsection{Stone specimens}

The authors extracted a sufficient number of archaeological "Mangabi" stone specimens from ruined stone blocks of a number of collapsed heritage buildings that was not registered in the Historic Jeddah city. The specimens were prepared into cubic shape of average sidelength $=50 \mathrm{~mm}$. Thirty-six cubic stone specimens were prepared that covers four main standard tests, which are: the apparent porosity, the water absorption and the bulk density for evaluating the physical properties, and the uniaxial compression test for evaluating the mechanical properties. For everyone of these four conducted tests, three specimens were achieved for each of the following experimental conditions to evaluate and compare the efficacy of the consolidating materials: i) the original (untreated) condition; ii) the treated samples with $\mathrm{CaLoSiL}^{\circledR}$; and iii) the treated samples with Wacker OH-100. Hence, twelve specimens were prepared for each of these three conditions to cover the four main tests.

Moreover, micro-specimens were achieved from the tested cubic specimens after finishing their standard tests. These micro-specimens were utilized for the evaluation of mirco-structure of the three testing conditions (i.e. the untreated and the two consolidated conditions). Hence, the mineralogical analyses using X-Ray Diffraction (XRD) and petrographical examination of the micro-structure (e.g. cavities, pores, etc.) using Digital Microscope (DM), Polarizing Microscope (PM) and Scanning Electron Microscopy (SEM) with EDX microanalysis were all achieved to these micro-specimens.

All thirty-six stone specimens, after preparation to the required cubic shape and dimensions $(50 \mathrm{~mm})$ for every test, were firstly washed with de-ionized water, and then were dried in an electrical oven "Memmert West Germany" at 105 ${ }^{\circ} \mathrm{C}$ for 24 hours to reach constant weight. Then, they were left at room temperature (20-23 ${ }^{\circ} \mathrm{C}$ ) for 2 hours to cool before they were weighed again, using a highly sensitive balance "CHYo-JK 180", after achieving constant weight for specimens. The present research compared between two types of consolidants that previous researches [8-11, 14-21] recommended their application for similar properties and conditions to the "Mangabi" limestone. The experimental evaluation compared between the traditional consolidant of Wacker $\mathrm{OH}-100$ with the modern nano-lime of ' CaLoSiL ${ }^{\circledR}$.

\subsection{The nano-lime 'CaLoSiL ${ }^{\circledR}$}

The $\mathrm{CaLoSiL}^{\circledR}$ is a Colloidal nanoparticles of lime for stone and plaster consolidation. It is produced by IBZSalzchemie GmbH \& Co.KG in Germany and used as a ready-to-use for stone and plaster consolidation [18]. It is composed of nano-particles of calcium hydroxide $\mathrm{Ca}(\mathrm{OH})_{2}$ suspended in different alcohols. Typical concentrations are produced between 5 to $50 \mathrm{gm} / \mathrm{litre}$. Either ethanol, iso-propanol or n-propanol is used as a solvent [18].

Treatment of stone with $\mathrm{CaLoSiL}^{\circledR}$ generally results in the formation of stable solid calcium hydroxide after evaporation of the alcohol. That converts into calcium carbonate in a way similar to traditional lime mortars by reaction with atmospheric carbon dioxide and after all alcohols completely evaporate. 
The technique of applying $\mathrm{CaLoSiL}^{\circledR}$ to stone specimens was as follows [18]. The dry specimens were firstly treated with a combination of CaLoSiL E5 (which contains 5 gm nano-lime per litre) and E25 ( $25 \mathrm{gm} / \mathrm{litre}$ ). The rationale being that the E5 will give greater penetration to start with, followed by the E25 to deliver maximum amounts of nano-lime to the structure of specimens. The CaLoSiL was applied with a soft hair brush, with six applications of E5 followed by two of E25 over a two-day period. In addition, the CaLoSiL E-50 (50 gm/litre) was added to soft "Mangabi" stone powder with $3: 1$ ratio (by weight) respectively, using medical syringes, into cracks, holes, voids and cavities (fossils traces) that were found in stone specimens during applications. The specimens were covered with polyethylene sheets, between applications, to prevent premature evaporation of the iso-propanol and ethanol, thus acquiring maximum penetration. A piece of water wetted gauzed cloth was placed on the treated surface of specimens, as calcium hydroxide requires both air and water for carbonization. Finally, the treated specimens were left at room temperature for 30 days to allow full carbonization process to complete. The selected concentrations of the CaLoSiL were applied according to the recommendations of the producing company and the previous experience of the authors in relevant consolidation works [17-18, 21].

\subsection{The Wacker $\mathrm{OH}-100$}

The Wacker OH-100 is a water-repellent silicate polymer that is used for binding, stabilizing and isolating weatherdamaged and friable stone wall surfaces. It is produced in liquid form ready-to-use as an ethyl silicate base. When applied, it penetrates through the capillaries deep into the construction material. The neutral catalyst promotes the reaction be- tween ethyl silicate and water from atmospheric humidity or the moisture in the capillary pores. A glass-like silica gel binder $\left(\mathrm{SiO}_{2}\right.$.aq.) is formed. The ethanol by product evaporates under standard conditions $\left(20{ }^{\circ} \mathrm{C} / 50 \%\right.$ r. h. $)$. Final hardness is reached after two weeks, when most of the ethyl silicate has been converted to silica gel [19-20]. It was found that using Wacker OH-100 in consolidation treatment for lime stones resulted in a noticeable increase in the surface hardness of treated specimens. Due to the fact that Wacker $\mathrm{OH}-100$ is based on the presence of moisture, it was selected to suit the atmosphere of Jeddah city with high humidity. In addition to the similarity of its composition in terms of the presence of quartz in the composition of the Mangabi stone (refer to the results of analyses and examination conducted by the authors). Wacker $\mathrm{OH}-100$ was applied by brushing on dry cubic specimens, brushing was achieved using two applications performed in the same day with a time interval of four hours. The same procedure was repeated two days later, and then the treated specimens were left at room temperature for 30 days, for allowing the polymerization process to complete.

\subsection{Testing and evaluating method- ology}

The density of stones is generally in direct proportion with their strength, toughness and stiffness of masonry material. Likewise, apparent porosity and water absorption are characteristics of masonry materials that indeed draw a true picture of moisture movement and storage, which play a key role in the durability of porous building materials [19-21]. State of conservation, durability and validity of the consolidating materials of heritage buildings' stones are evaluated through enhancement in the physical, petrographic and mechanical properties 
of the stone specimens after treatment. Besides, the improvement in these properties can enhance the overall mechanical strength of the masonry walls, which is the main aim for the consolidation process. Hence, the following experimental works on the "Mangabi" stone specimens were conducted. Besides, the penetration and deposition mechanism of these consolidants within internal structure and in the surface of these stone specimens with their effect on its morphological features and surface appearance were examined by digital and scanning electron microscopy after 30 days from their application, as the polymerization and carbonation processes of the consolidants were completed.

\subsection{Physical, mechanical, miner- alogical and petrographical evaluation works}

For the physical and mechanical properties, a group of standard tests were carried out on the prepared stone specimens before and after conducting the consolidation treatment. All specimens were cut to cubic shape of average dimensions 50 $\times 50 \times 50 \mathrm{~mm}^{3}$. For evaluating physical properties of bulk density, apparent porosity and water absorption relevant standard test for each test was conducted following the ASTM C97 specifications [22]. Besides, the mechanical properties were evaluated from the standard axial compression test on the cubic stone specimens, following ASTM C170 specifications [23]. All tests were performed in the 'Material Test Lab' of the 'Central Unit for Analysis and Scientifically Services (CUASS)' of the 'National Research Centre' in Cairo, Egypt, except the SEM analysis that were conducted in central laboratories sector in the 'Egyptian Mineral Resources Authority'. All tests were conducted at room temperature (21-23 ${ }^{\circ} \mathrm{C}$ ) and humidity (50-60\%). Besides, calibration for the testing devices was properly and continuously conducted during all tests.

\subsubsection{Mechanical tests}

The standard axial compression tests over the nine cubic specimens $(50 \mathrm{~mm}$ average length) were conducted in the 'CUASS' of the 'National Research Centre' in Cairo. The testing machine type is 'GALDABINI-QUASAR 600' (made in Italy) that automatically records the deformation with measuring accuracy of $0.001 \mathrm{~mm}$.

\subsubsection{X-ray diffraction (XRD) Analysis}

The mineralogical composition was determined by X-ray diffraction analysis, which was performed using a PANAnalytical X-Ray Diffraction equipment model X'Pert-PRO. The operating conditions were: Secondary Monochromator, Cu-radiation $(\lambda=1.542 \AA)$ at $45 \mathrm{~K} . \mathrm{V} ., 35$ M.A., with applied scanning speed of 0.04 / second. The recoded diffraction peaks for $2 \theta$ were between $2 \theta$ and $60 \theta$, where the corresponding spacing $(\mathrm{d}, \AA)$ and relative intensities (I/Io) were obtained. The diffraction charts and relative intensities are obtained and compared with 'ICDD' files for identification work.

\subsubsection{Digital Microscope (DM)}

The micro-structure (e.g. cavities, pores, etc.) of both untreated and consolidated specimens were examined using Digital Microscope (DM), which was performed at the central laboratories sector in the Egyptian Mineral Resources Authority (EMRA). This petrographic study applied optical polarizing microscope of model 'Olympus BX51 TF' (made in Japan), attached with digital camera under magnification of $20 \mathrm{X}$ up to $40 \mathrm{X}$. 


\subsubsection{Scanning Electron Microsco- py (SEM) with EDX microa- nalysis}

The Scanning Electron Microscope (SEM) examination for the treated and untreated "Mangabi" stone specimens was also performed at the central laboratories sector (EMRA), using SEM model Quanta 250 FEG (Field Emission Gun) attached with EDX unit (Energy Dispersive X-ray Analyses), with accelerating voltage $30 \mathrm{~K} . \mathrm{V}$. and magnification $14 \mathrm{x}$ up to $1000000 x$. This microscope is used in evaluating the morphological features of the studied stone specimens, in determining the penetration and spreading of consolidation materials and in defining the deposition of consolidants within the structure of the stones. Also, it examines the ability for binding, cohesion and encapsulating of granules and components. Finally, it helps comparing the results of the examination of consolidated specimens with standard specimens (unconsolidated) to assess the effectiveness and efficiency of these materials in the strengthening of weak limestone blocks.

\section{Results and discussion}

\subsection{Stone characterization}

The petrographic study revealed that the studied "Mangabi" stone specimens can be classified as fossiliferous limestone (i.e. Shelly limestone). It is cut from a fine-grain to moderate fossiliferous carbonate rock, which is consisting of quartz grains embedded mainly in limemudstone (i.e. Micrite). The rock is highly fossiliferous that is composed of mollscan shells, echinoid spines, benthonic foraminifera and algal skeletal fragments. The shell fragments reveal the original internal microstructure. Fig. 3 showed the thin sections of "Mangabi" stone specimens under polarizing microscope. Previous results were confirmed by the
X-Ray diffraction (XRD) pattern, which showed the specimens are composed of Calcite $\left(\mathrm{CaCO}_{3}\right)$ as a major mineral (It is designated by ' $\mathrm{Ca}$ '), besides traces of Quartz $\left(\mathrm{SiO}_{2}\right)$, Halite $(\mathrm{NaCl})$ and Hematite $\left(\mathrm{Fe}_{2} \mathrm{O}_{3}\right)$ that are either ingredients, salts or impurities (less than 5\%), see Fig. 4.

The elemental analysis by EDX agrees with the mineralogical study made by XRD. The chemical data acquired by EDX unit showed that the main elements of "Mangabi" limestone are: 'Ca', 'O', 'C' and 'Si', related with Calcite and Quartz, as detected by XRD. 'Na' and 'Cl' are related with the presence of Halite salt. The minor amount of 'Fe' is related with the hematite. The other elements do not have significant amounts that point to other minor mineral phases which are not detectable by XRD, as shown in Fig. 5 and Table. 1

\subsection{Physical and mechanical prop- erties tests' results}

The results of the previous tests for treated and untreated "Mangabi" stone specimens (Table (2) and Fig. 6) clearly revealed that both consolidants have significantly affected the physical and mechanical properties of the treated stone specimens, as the values of the bulk density and the compressive strength increased, while the values of the apparent porosity and the water absorption decreased. Besides, the nano-lime (CaLoSiL) provided improved consolidating for the stones' results as follows:

\subsubsection{Apparent porosity}

The nano-lime (CaLoSiL) consolidation had a greater impact on the pore structure of "Mangabi" stone specimens than the effect of Wacker OH-100. The apparent porosity value of the studied specimens 


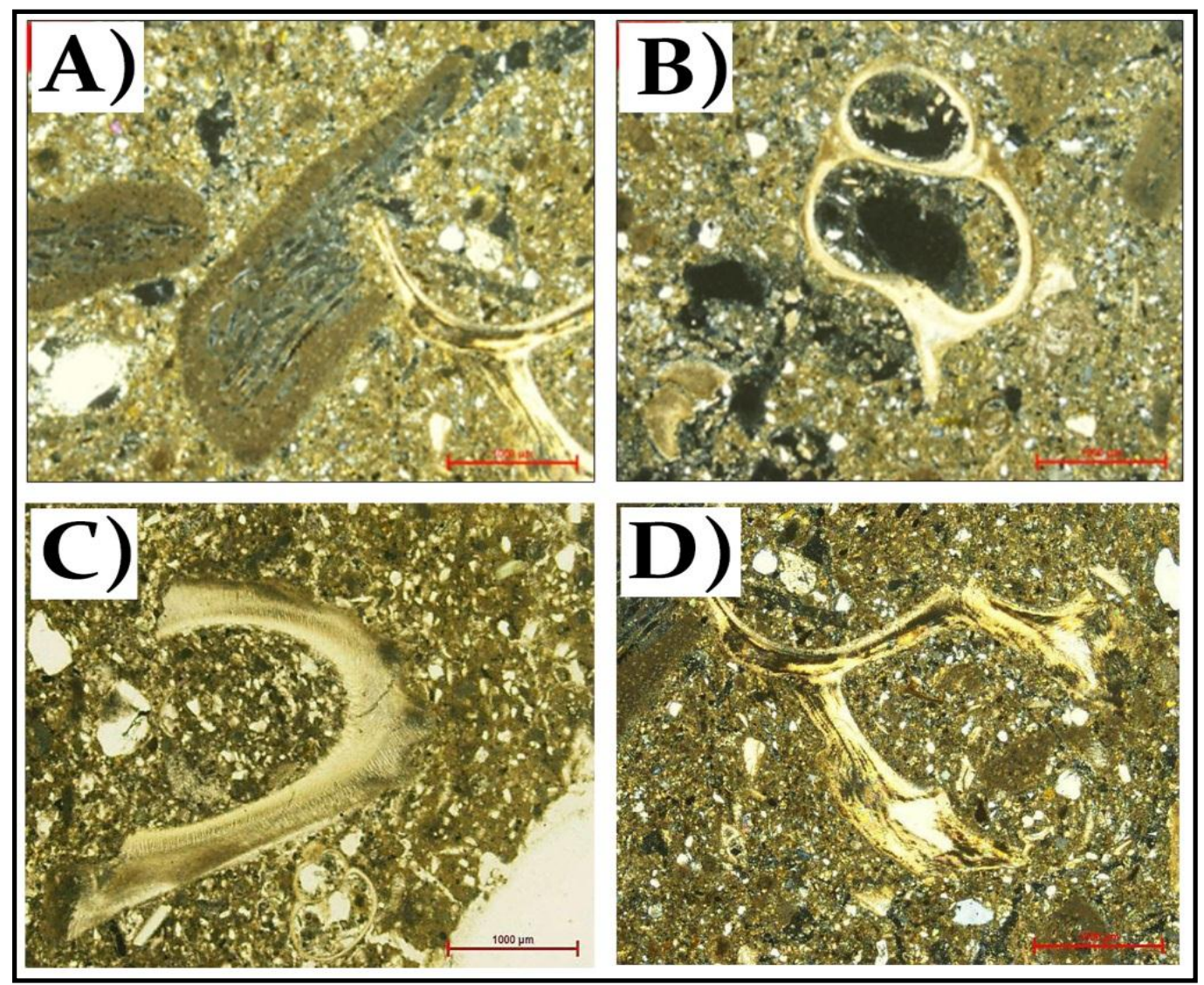

Fig. 3: (A, B, C and D) Polarizing (PM) micrographs of the studied "Mangabi" fossiliferous limestone, showing the shelly micro-structure.

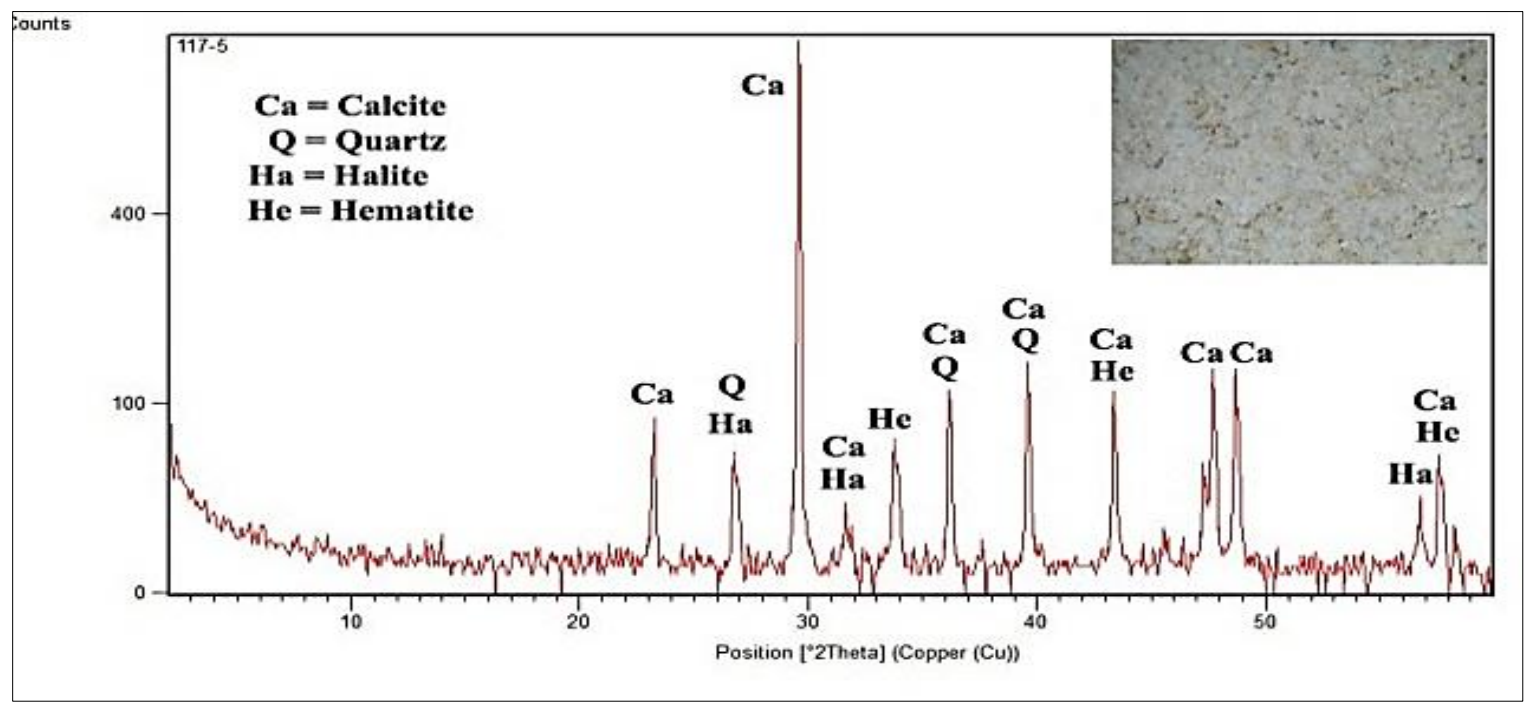

Fig. 4: XRD pattern of the studied fossiliferous limestone specimen. 


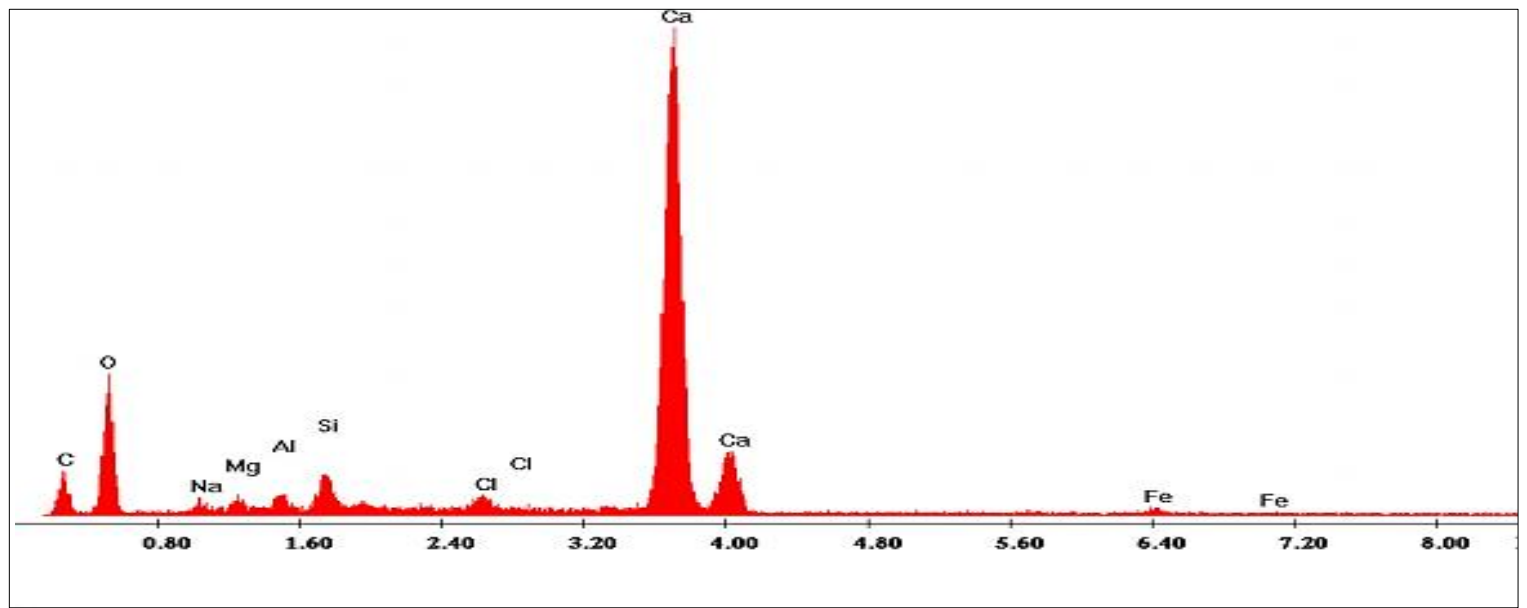

Fig. 5: SEM-EDX spectrum of the studied fossiliferous limestone specimen.

Table 1: Quantitative EDX microanalysis (\% wt) of the studied fossiliferous limestone specimen.

\begin{tabular}{|c|c|}
\hline Main constituents & Concentration (wt\%) \\
\hline $\mathrm{C}$ & 7.11 \\
\hline $\mathrm{O}$ & 37.55 \\
\hline $\mathrm{Na}$ & 1.21 \\
\hline $\mathrm{Mg}$ & 1.13 \\
\hline $\mathrm{Al}$ & 1.14 \\
\hline $\mathrm{Si}$ & 2.30 \\
\hline $\mathrm{S}$ & $\mathbf{0 . 2 6}$ \\
\hline $\mathrm{Cl}$ & 1.13 \\
\hline $\mathrm{Ca}$ & 46.83 \\
\hline Fe & 1.61 \\
\hline
\end{tabular}


(Table 2) before treatment ranged between $27.1 \%$ and $31.3 \%$ with an average of $29.4 \%$, while it ranged after treatment with nano-lime between $5.4 \%$ and $8.9 \%$, with an average of $7.3 \%$. The decrease in porosity ratio due to consolidation treatment is only $75.1 \%$. Whilst, the apparent porosity value of the studied specimens after treatment with Wacker $\mathrm{OH}-100$ ranged between $10.0 \%$ and $11.5 \%$, with an average of $10.6 \%$, and its decrease ratio due to consolidation treatment was only $63.9 \%$. Hence, CaLoSiL reduced the stone's porosity more than Wacker (Fig. $6)$.

\subsubsection{Water absorption}

The standard water absorption tests that were conducted for the treated and untreated studied "Mangabi" specimens revealed that the two consolidants used in this study succeeded in reducing the water absorption rates of the specimen. Nano-lime consolidant had significantly affected the water uptake of the studied specimens than Wacker OH-100. The absorption value (Table 2) of the studied specimens before treatment ranged between $18.5 \%$ and $20.5 \%$, with an average of $19.7 \%$. After treatment with nanolime, it ranged between $3.3 \%$ and $5.0 \%$, with an average of $4.4 \%$. The decrease of water absorption ratio due to the nanolime treatment was only $77.6 \%$. While the water absorption value after treatment with Wacker OH-100 ranged between $6.2 \%$ and $6.8 \%$, with an average of $6.4 \%$ and an overall reduction in the water absorption ratio of $67.5 \%$. So, CaLoSiL reduced the stone's water absorption more than Wacker (Fig. 6).

\subsubsection{Bulk density}

The two studied consolidants moderately raised the bulk density of the "Mangabi" stone specimens. The bulk density of the studied specimens (Table 2) before treatment ranged between 1.45 and 1.54 $\mathrm{gm} / \mathrm{cm}^{3}$, with an average of $1.48 \mathrm{gm} / \mathrm{cm}^{3}$. While after treatment with nano-lime, it ranged between 1.60 and $1.76 \mathrm{gm} / \mathrm{cm}^{3}$, with an average of $1.67 \mathrm{~g} / \mathrm{cm}^{3}$. The decrease ratio in bulk density due to its consolidation is only $12.8 \%$. While the bulk density of the studied specimens after treatment with Wacker $\mathrm{OH}-100$ ranged between 1.56 and $1.68 \mathrm{gm} / \mathrm{cm}^{3}$ with an average of $1.64 \mathrm{gm} / \mathrm{cm}^{3}$. The decrease ratio in bulk density due to its consolidation is only $10.8 \%$. Hence, CaLoSiL raised the stone's density rather than Wacker (Fig. 6).

\subsubsection{Compressive strength}

The standard compressive test was also conducted for the "Mangabi" stone specimens both before and after consolidation treatments (Fig. 7).

The average compressive strength of the untreated specimens was $7.3 \mathrm{~N} / \mathrm{mm}^{2}$ and increased to about $12.1 \mathrm{~N} / \mathrm{mm}^{2}$ after treatment by nano-lime, with an average increase percentage of $65.7 \%$. Treatment by Wacker provided average strength of $9.4 \mathrm{~N} / \mathrm{mm}^{2}$, with an increase percentage of $28.7 \%$. The significant increase in compressive strength resulting from strengthening by nano-lime that Wacker can be attributed to the good adhesion of the nano-lime after setting. Besides, its higher ability in forming bridges of nanoCalcite on the grains of the treated stone, in achieving a good bonding between the grains and in filling all cracks, holes and cavities. Hence, the nano-lime successfully consolidated the fragile stone structure and enhanced its mechanical properties.

\subsection{Digital and scanning electron microscope results}

The Digital Microscope (DM) and Scanning Electron Microscope (SEM) were applied in evaluating the effect of the two consolidating materials to the micro- 


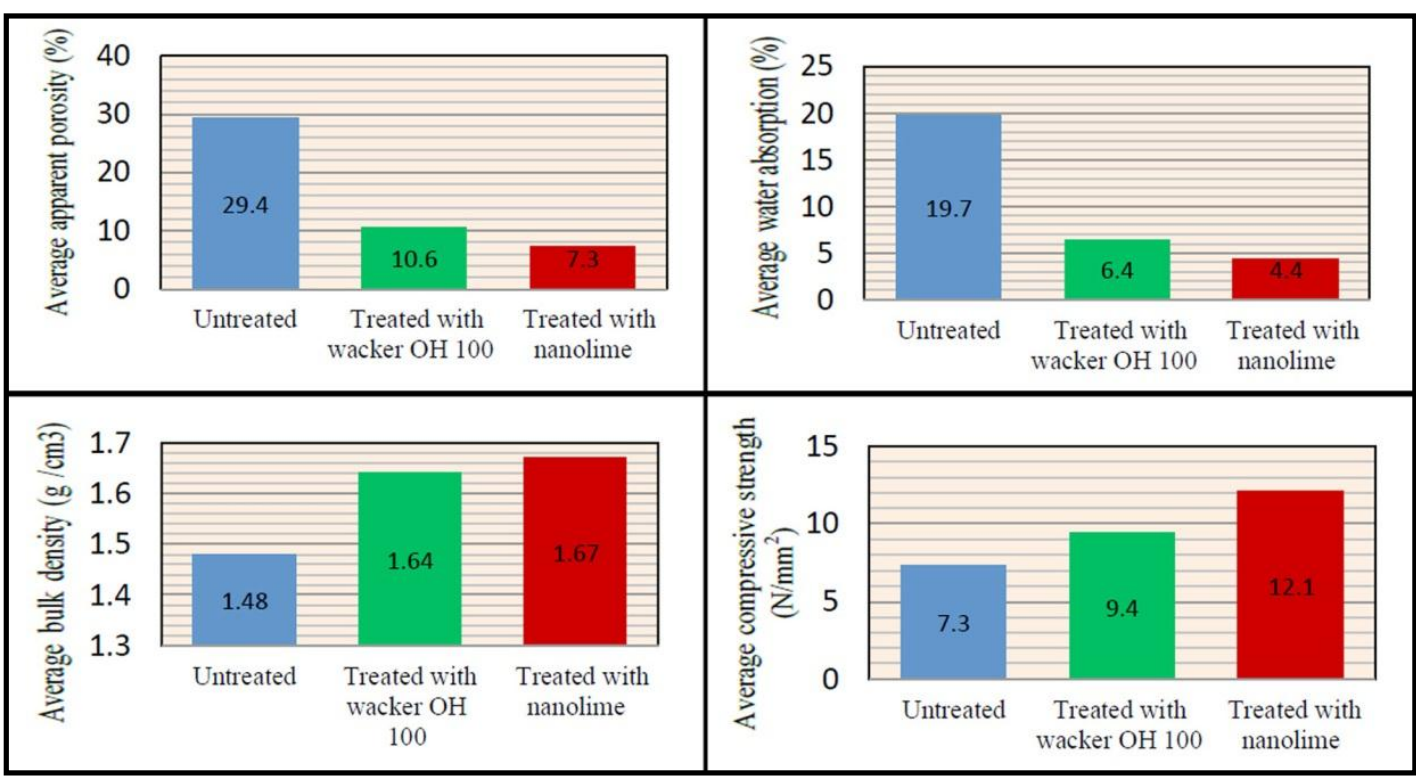

Fig. 6: The effect of consolidation materials on the properties of the tested "Mangabi" stone specimens.

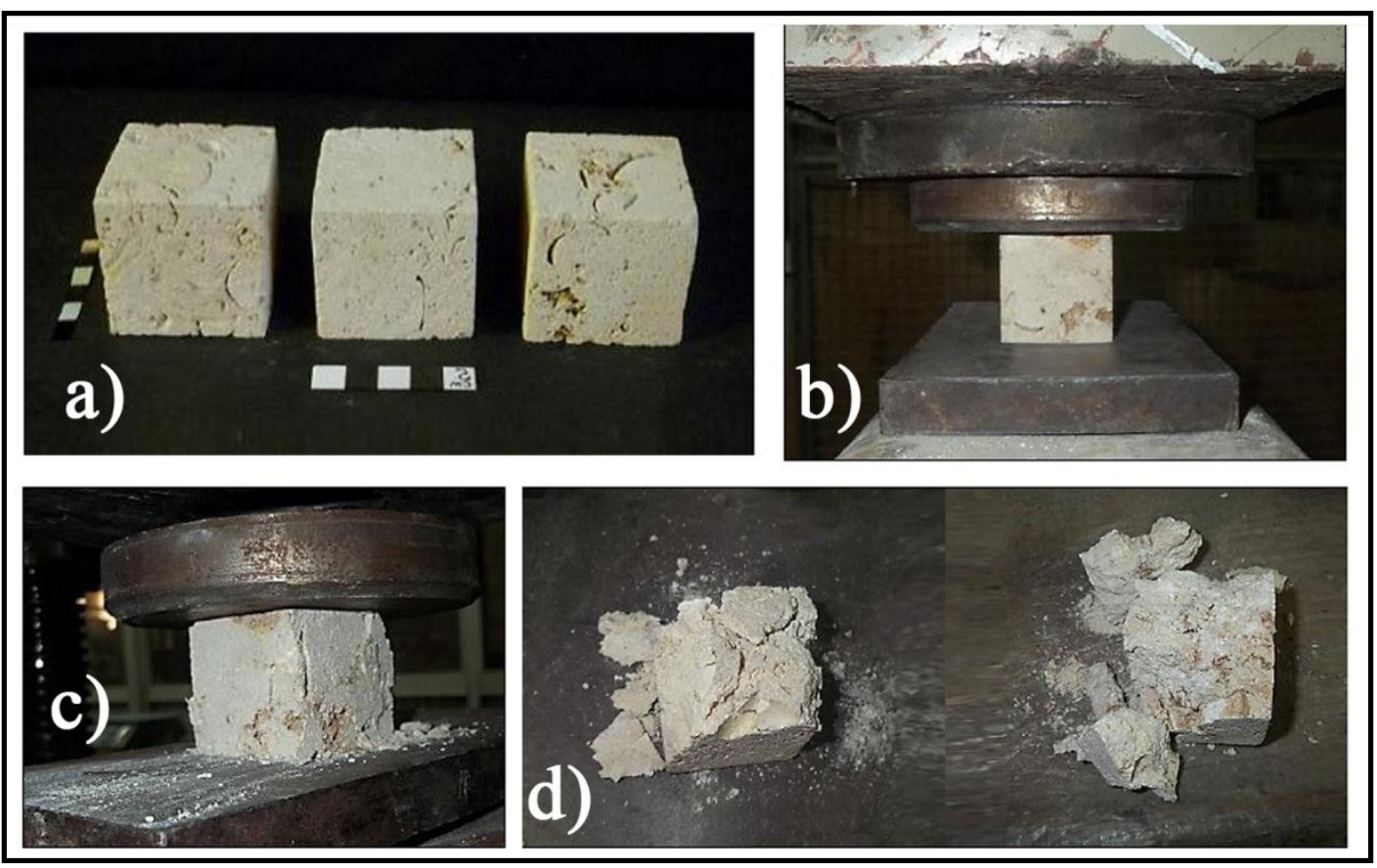

Fig. 7: The standard mechanical test for the original (untreated) cubic stone specimens: a) the specimens; b) the testing setup; c) cracking of specimens; d) final failure crushing of specimens. 
Abdel-Aty Y. Y., Mahmoud H. S., Al-Zahrani A. A.

Table 2: Physical and mechanical properties of the "Mangabi" stone specimens before and after treatments (S1, S2 and S3 are the three specimens of each condition).

\begin{tabular}{|c|c|c|c|c|c|}
\hline \multirow{2}{*}{ Tested Property } & \multirow{2}{*}{ Specimen Number } & \multicolumn{4}{|c|}{ Results } \\
\hline & & S1 & $\mathbf{S 2}$ & S3 & Average \\
\hline \multirow{5}{*}{$\begin{array}{c}\text { Bulk } \\
\text { Density }\left(\mathrm{g} . / \mathrm{cm}^{3}\right)\end{array}$} & Untreated & 1.54 & 1.46 & 1.45 & 1.48 \\
\hline & Treated with CaLoSiL & 1.60 & 1.76 & 1.65 & 1.67 \\
\hline & Increase $\%$ & \multicolumn{4}{|r|}{12.8} \\
\hline & Treated with Wacker OH-100 & 1.56 & 1.68 & 1.61 & 1.64 \\
\hline & Increase $\%$ & \multicolumn{4}{|r|}{10.8} \\
\hline \multirow{5}{*}{$\begin{array}{c}\text { Apparent Porosity } \\
(\%)\end{array}$} & Untreated & 31.1 & 27.1 & 29.9 & 29.4 \\
\hline & Treated with CaLoSiL & 7.8 & 8.9 & 5.4 & 7.3 \\
\hline & Decrease $\%$ & \multicolumn{4}{|r|}{75.1} \\
\hline & Treated with Wacker OH-100 & 10.3 & 11.5 & 10 & 10.6 \\
\hline & Decrease $\%$ & \multicolumn{4}{|r|}{63.9} \\
\hline \multirow{5}{*}{$\begin{array}{c}\text { Water absorption } \\
(\%)\end{array}$} & Untreated & 20.3 & 18.5 & 20.5 & 19.7 \\
\hline & Treated with CaLoSiL & 4.9 & 5.0 & 3.3 & 4.4 \\
\hline & Decrease $\%$ & \multicolumn{4}{|r|}{77.6} \\
\hline & Treated with Wacker OH-100 & 6.2 & 6.8 & 6.2 & 6.4 \\
\hline & Decrease $\%$ & \multicolumn{4}{|r|}{67.5} \\
\hline \multirow{5}{*}{$\begin{array}{c}\text { Compressive } \\
\text { Strength }\left(\mathbf{N} / \mathbf{m m}^{2}\right)\end{array}$} & Untreated & 6.6 & 8.5 & 6.9 & 7.3 \\
\hline & Treated with CaLoSiL & 11.8 & 13.4 & 11.1 & 12.1 \\
\hline & Increase $\%$ & \multicolumn{4}{|r|}{65.7} \\
\hline & Treated with Wacker OH-100 & 8.7 & 9.0 & 10.7 & 9.4 \\
\hline & Increase $\%$ & \multicolumn{4}{|r|}{28.7} \\
\hline
\end{tabular}


structure of the "Mangabi" stone specimens. The DM imaging and SEM micrographs (Fig. 8 and Fig. 9) of the untreated "Mangabi" stone specimens revealed that the specimens appeared in very poor state as they had many pores, holes and cavities. In addition, the Calcite grains are very fragile, loose and significantly disintegrated. While, the two applied consolidation products in this study succeeded in covering the crystals of the stone specimens with polymeric networks of Wacker $\mathrm{OH}-100$ and in forming bridges of nano-Calcite on the grains of the treated stone specimens, in addition to improving the connection between them and filling the big pores and cavities around. The specimens treated by nano-lime showed the occurrence of coherence and cohesion of the components of the stone specimen, and a very good bond between the fragile and loose mineral particles, as the consolidant encapsulate them well. This attributed to the significant diffusion of the consolidating material within internal voids and micro-structure of the specimen that filling all the pores, holes, cavities and micro-cracks in it, by precipitating the nano-particles in the form of very small particles inside, which consolidated the weak stone micro-structure.

The specimens treated by Wacker $\mathrm{OH}-$ 100 showed the occurrence of good bonding between fragile and loose mineral particles, and filling most of the pores, holes, cavities and micro-cracks inside the specimen. Although, a few holes and cavities were found open in some areas of the micro-structure, as Wacker did not fill them completely. In addition, it deposited on the specimen surface irregularly, and formed a thin layer over it.

\section{Conclusions}

This paper reported that the physical and mechanical properties of the local "Mangabi" stone that was intensively used in constructing the masonry walls of heritage buildings at Historic Jeddah (KSA) could be enhanced by means of consolidants that filling the pores and cavities of this vulnerable fossiliferous limestone. Hence, the structural safety levels can be greatly enhanced for the heritage buildings and their URM loadbearing walls. This paper compared between the basic properties of these stones before and after consolidation with either nano-lime of CaLoSiL and Wacker OH-100. For this purpose, standard physical tests of measuring apparent porosity, water absorption, bulk density and uniaxial compressive strength were conducted for standard stone specimens that were taken from ruins of a number of unregistered collapsed heritage buildings in Historic Jeddah. Besides, petrographical evaluation of microstructure (e.g. cavities, pores, etc.) using DM and SEM micro-graphy was achieved.

The untreated specimens reported very poor properties, which are considered the main reasons for the "Mangabi" deterioration and its negative impact on the overall mechanical strength of the URM walls of the heritage buildings. The consolidation of the stone specimens using nano-lime of CaLoSiL provided improved results for all tested properties and under petrographic imaging than Wacker OH-100, although both improved the mechanical durability and significantly increased the strength of the treated specimens. Besides, the Wacker deposited on the specimen surface irregularly, and formed a thin layer over it, while these side-effects were not reported with the nano-lime. The CaLoSiL increased the bulk density of the stone specimens (on the average) by $12.8 \%$, decreased the apparent porosity by $75.1 \%$ and water absorption by about $77.6 \%$ and increase the mechanical compressive strength by $65.7 \%$. It is worth mentioning that the conclusions of this study were 

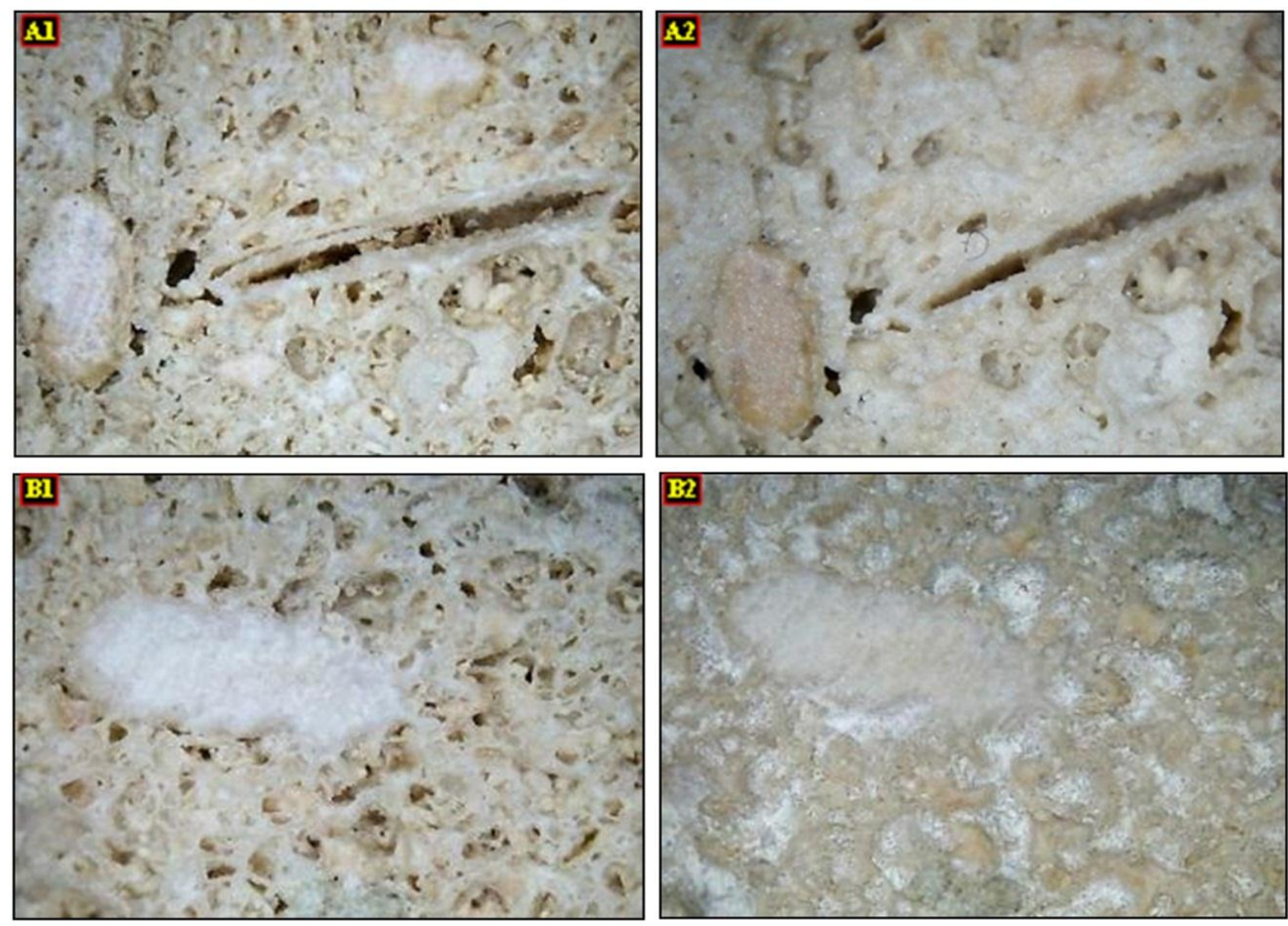

Fig. 8: Digital Microscope (DM) images of the "Mangabi" stone specimens before and after the consolidation treatment, magnification $100 \mathrm{X}$ : (A1) the stone before the treatment, (A2) the same area after the treatment with Wacker OH-100, (B1) the stone before the treatment, (B2) the same area after the treatment with CaLoSiL.
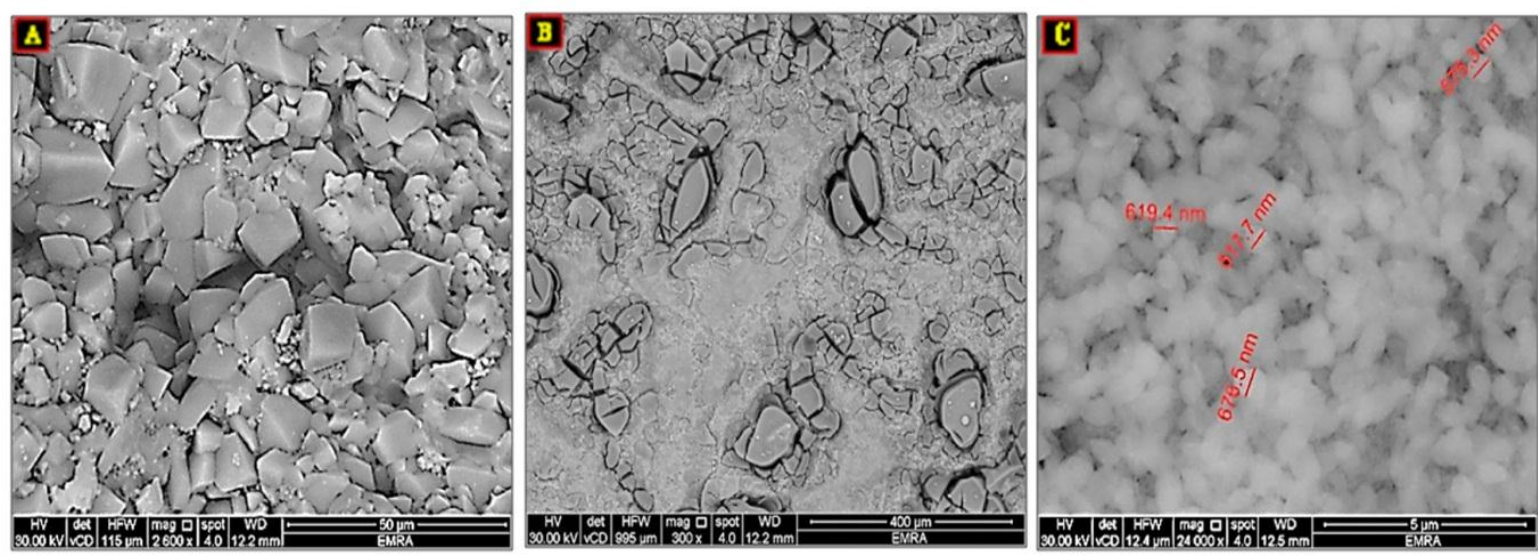

Fig. 9: SEM micrographs of the "Mangabi" stone specimens before and after the treatment: (A) the stone before the treatment, $(B)$ the stone after the treatment with Wacker OH-100, (C) the stone after the treatment with CaLoSiL. 
merely based on evaluation of the shortterm efficacy, as environmental conditions greatly affect the curing conditions of nano-lime. Hence, more field tests are highly recommended to evaluate the efficiency of the nano-lime and to optimize the application conditions to consolidate archaeological "Mangabi" stones in Jeddah's Heritage buildings. Generally, this study revealed that fossiliferous limestone blocks in the Jeddah's heritage buildings can be strengthened and improved their quality by consolidating them with iso-propanol and ethanol based nano-lime without displaying significant changes.

\section{References}

1. M. Bagader, The Old City of Jeddah: from a Walled City to a Heritage Site, WIT Transactions on the Built Environment, Vol. 143, 2014, p. 365.

2. I. Crespin, "Fossiliferous Limestone from Menapi Bay, Cape Vogel Peninsula", Mineral Resources, Mineral Economics Library, Austrlia, 1955, p. 1.

3. S. Holmes and B. Rowan, "Building with Lime \& Lime Stabilized Soil", 2nd Edition, Pakistan, 2015, p. 3.

4. S. M. Al-lyaly, "The Traditional House of Jeddah: a Study of the Interaction between Climate Form and Living Patterns", Ph.D. thesis, Department of Architecture, University of Edinburgh, 1990, p. 46.

5. M. R. Valluzzi et al., "Mechanical behaviour of historic masonry structures strengthened by bed joints structural repointing", Construction and Building Materials Vol. 19, 2005, pp. 6466.

6. S. M. Kaya, "Inventory of Repair and Strengthening Methods with Iron and Steel", M.Sc. Dissertation, Dalhousie University, Halifax, Nova Scotia, 2013, p. 5.
7. M. H., Shukri, The Rise and Fall of the Coral wall, MHS Architectural Office, Jeddah, 2012, p. 17.

8. R.P.J. Van Hees, B. Lubelli, T. Nijland, A. Bernardi, "Compatibility and performance criteria for nanolime consolidants", Proceedings of the 9th International Symposium on the Conservation of Monuments in the Mediterranean Basin Monubasin, Ankara, 3-5 June 2014, p. 167-188.

9. L. Toniolo, A. Paradisi, S. Goidanich, G. Pennati, Mechanical behavior of lime-based mortars after surface consolidation, Construction Building Materials, Vol. 25, 2010. pp. 1553-1559.

10. A.P. Ferreira Pinto and J. D. Rodrigues, Consolidation of carbonate stones: Influence of treatment procedures on the strengthening action of consolidants, Journal of Cultural Heritage, Vol. 12, 2011, p. 11.

11. G. Borsoi, B. Lubelli, R. Hees, R. Veiga, A.S. Silva, Understanding the Transport of Nano-lime Consolidants within Maastricht Limestone, Journal of Cultural Heritage, Vol. 18, 2016, pp. 242-243,

12. J. Zhao, and B.B. Broms, "Mechanical and Physical properties of the weathered Bukit Timah granite of Singapore", Proceeding of the ISRM Symposium. Geotechnical Engineering of Hard Soils-Soft Rocks, 1993, pp. 883-890.

13. E.T. Brown, Rock characterization, testing and monitoring-ISRM suggested methods, Pergamon Press, Oxford, 1981, p 211,

14. B. Guruprasadi, A. Ragupathy, T.S. Badrinarayanan, K.B. Rajkumar, The stress impact on mechanical properties of rocks in hydro fracturing technique, Int. Journal of Engineering Science and Technology, Vol. 4, Issue 2, 2012, pp. 571-580.

15. M.B. Al-Qahtani, and E.S. Abo-Seif, "Effect of animal borings on geotech- 
nical properties of coralline limestone in NW Jeddah City", Red Sea Coast, Saudi Arabia, Arab, Journal of Geoscience, 2013. p. 4978.

16. A. Otero et al., "An Overview of Nanolime as a Consolidation Method for Calcareous Substrates", Geconservación, Vol. 1, Issue 11, 2017, p. 3.

17. P. D'Armada and E. Hirst, Nano-lime for consolidation of plaster and stone, 21. Journal of architectural conservation, Vol. 181, 2012, pp. 63-80.

18. IBZ-Salzchemie GmbH \& Co.KG, "Technical Leaflet of CaLoSiL ${ }^{\circledR}$, www.ibz-freiberg.de.

19. R.A. Al-Omary, M. Al-Naddaf, W. Al Sekhaneh, Laboratory Evaluation of Nanolime Consolidation of Limestone Structures in the Roman Site of 23. Jerash, Jordan, Mediterranean
Archaeology and Archaeometry, Vol. 18, No 3, 2018, p. 36.

20. Z. Slížková and D. Frankeová, "Consolidation of Porous Limestone with Nanolime Laboratory Study", 12th International Congress on the Deterioration and Conservation of Stone Columbia University, New York, 2012, pp.1-2.

1. C. Lucian, Engineering Properties of Building Materials in Historic Buildings in Bagamoyo (Tanzania), International Journal of Engineering and Innovative Technology (IJEIT), Volume 3, Issue 9, 2014, p. 15.

22. ASTM C97, Absorption and Bulk Specific Gravity of Natural Building Stone, 1990.

23. ASTM C170, Compressive Strength of Natural Building Stone, 1990. 